\title{
Comparison of Prostaglandin Analog Treatment Patterns in Glaucoma and Ocular Hypertension
}

\author{
Ji Haeng Heo, PhD; Karen L. Rascati, PhD; James P. Wilson, PhD; \\ Kenneth A. Lawson, PhD; Kristin M. Richards, PhD; and Radhika Nair, PhD
}

\begin{abstract}
BACKGROUND: Prostaglandin analogs (PGAs) are considered an initial therapy to manage increased intraocular pressure (IOP) for patients with glaucoma. When the initial PGA treatment fails to lower IOP adequately, the patient may add or change medications or have surgery/laser treatment.

OBJECTIVE: To compare medication adherence, duration of therapy, and treatment patterns among 3 PGAs - latanoprost, travoprost, and bimatoprost-as initial therapies for patients with glaucoma or ocular hypertension.

METHODS: This was a retrospective cohort study using administrative claims data. The cohort consisted of patients newly diagnosed with glaucoma or ocular hypertension with at least 1 prescription claim for latanoprost, travoprost, or bimatoprost and enrolled in a Medicare Advantage plan between 2007 and 2012. The 24-month medication possession ratio (MPR) was used to measure medication adherence. Discontinuation of firstline PGA therapy was defined as nonpersistence (90-day gap allowance) of the index PGA or a change in therapy during the 24-month follow-up period. Types of second-line therapy (i.e., switch, addition, and surgery) were identified. The 1:1:1 propensity score matching was used.
\end{abstract}

RESULTS: Patients who met the inclusion criteria were propensity score matched, resulting in 1,296 patients per PGA group. Latanoprost users showed higher adherence $(50.1 \%)$ than travoprost $(48.8 \%)$ and bimatoprost $(43.0 \%)$ users. The latanoprost and travoprost groups had significantly higher MPRs than bimatoprost $(P<0.0001)$. The latanoprost group showed significantly longer duration of first-line therapy (372 days) than the bimatoprost group ( 343 days; $P=0.003$ ) but not the travoprost group (361 days). After controlling for demographic and clinical characteristics, a Cox proportional hazards model showed that the travoprost and bimatoprost groups had a higher risk of discontinuation of first-line therapy than the latanoprost group $(P<0.0001)$. The percentage of patients continuing on the index PGA without treatment pattern change (i.e., switches, additions, and surgery) was higher for latanoprost users (52.9\%) compared with travoprost $(39.0 \%)$ or bimatoprost users $(42.1 \% ; P<0.001)$.

CONCLUSIONS: Patients who used latanoprost as their initial therapy were more likely to adhere and persist to the index PGA compared with bimatoprost users. The latanoprost group demonstrated a lower risk of discontinuing first-line therapy than the travoprost and bimatoprost groups. The results may assist ophthalmologists in determining the optimal management of this patient population with respect to treatment patterns.

J Manag Care Spec Pharm. 2019;25(9):1001-10

Copyright $\odot 2019$, Academy of Managed Care Pharmacy. All rights reserved.

\section{What is already known about this subject}

Prostaglandin analogs (PGAs) have been shown to have a greater ability to reduce intraocular pressure than other prescribed therapeutic classes for patients with glaucoma.

PGAs are associated with greater persistence than other classes of medications.

\section{What this study adds}

Patients who used latanoprost as their initial therapy had a 7\% higher adherence rate than the bimatoprost group during the 24-month follow-up.

The travoprost and bimatoprost groups had a 41\%-48\% higher risk of discontinuing first-line therapy than the latanoprost group. - In second-line therapy, the travoprost group was 43\% more likely to add alternative medications than latanoprost users.

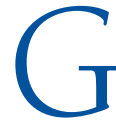
laucoma is defined as an optic neuropathy characterized by specific structural findings in the optic disc and specific functional deficits. ${ }^{1}$ In the United States, there were approximately 2.7 million Americans aged 40 years and older with glaucoma in 2010. ${ }^{2}$ Glaucoma is a progressive condition caused by the degeneration and death of retinal ganglion cells and their axons that form the optic nerve. This degeneration causes damage to the optic nerve, resulting in visual field reduction and blindness. ${ }^{3}$ After cataracts, glaucoma is the second common cause of legal blindness in the United States, and the leading cause of irreversible vision loss. ${ }^{4,5}$ Elevated intraocular pressure (IOP) is considered the most significant risk factor for the development of glaucoma and ocular hypertension. ${ }^{6}$ The reduction of IOP at any point along the spectrum of disease severity can reduce progression. ${ }^{7}$ Glaucoma can be treated with topical eyedrops, laser surgery, or a combination of these methods. Prostaglandin analogs (PGAs) are considered as initial medical therapy. ${ }^{8,9}$ PGAs have become increasingly popular since around the year 2000 (latanoprost was approved by the U.S. Food and Drug Administration in 1996, and bimatoprost and travoprost were approved in 2001) because they are efficacious and convenient (once-daily application) and have minimal systemic side effects. ${ }^{8,10}$ Among topical eyedrops, PGAs have been shown to have a greater ability to reduce IOP and lower the risk of adverse events than other prescribed 
ophthalmic therapeutic classes, including beta blockers and carbonic anhydrase inhibitors (CAIs).,11,12

Poor adherence to glaucoma medications may be associated with glaucoma progression. Successful treatment outcomes for chronic diseases, such as glaucoma, usually require daily use of medication to minimize disease progression. Sleath et al. (2015) reported that patients who were more than $80 \%$ adherent to glaucoma eyedrops were significantly less likely to have worse defect severity (odds ratio $[\mathrm{OR}]=0.17 ; 95 \%$ confidence interval $[\mathrm{CI}]=0.04-0.76) .{ }^{13}$ Mansberger et al. (2010) found that patients with poor adherence to medical and surgical recommendations had increased glaucomatous progression when compared with those with good adherence $(50 \%$ vs. $10 \%$; $\mathrm{OR}=8.6 ; \mathrm{P}<0.001) .{ }^{14}$ Glaucoma medications are only effective when they are used consistently and administered properly. A failure of patients to achieve optimal persistence for the asymptomatic disease of glaucoma can have important health consequences such as a higher risk of elevated IOP levels and eventual blindness. ${ }^{15,16}$

PGAs are associated with greater persistence than other classes of medications. For example, Nordstrom et al. (2005) found PGAs to be associated with longer persistence than beta blockers (hazard ratio $[\mathrm{HR}]=0.40 ; 95 \% \mathrm{CI}=0.35-0.44$ ). The hypothesized reasons for the increased persistence with PGAs included greater efficacy lowering IOP, fewer side effects, and a favorable dose regimen (once a day). ${ }^{17}$ Schwartz et al. (2004) compared persistence to PGAs with beta blockers for 12 months among patients with primary open angle glaucoma and showed that the proportions of patients continuing on the index medication were 39\% versus $25 \%$, respectively, because PGAs had higher tolerability and convenience. ${ }^{18}$ Other studies found a greater 12-month persistence for patients prescribed latanoprost than for IOP-lowering medications of different classes such as beta blockers and CAI. ${ }^{19,20}$ In the United Kingdom, patients treated initially with latanoprost monotherapy were consistently found to be significantly more likely to continue therapies compared with those treated with beta blockers, CAI, or brimonidine. ${ }^{21}$

Most studies comparing medication adherence (consistent use of medications as prescribed) or persistence (use of medication continuously for a specific time period) among latanoprost, travoprost, and bimatoprost reported that latanoprost users had higher adherence or persistence compared with other PGAs. ${ }^{15,16,22-25}$ While most studies assessed only persistence, Stein et al. (2015) compared adherence, using the metric of proportion of days covered (PDC). ${ }^{26}$ Only Wilensky et al. (2006) studied adherence and persistence for PGA therapy. ${ }^{27}$ However, they evaluated only initial PGA and did not assess treatment changes such as additions, switches, and surgeries after the initiation of PGAs in the long-term follow-up.
Despite the IOP-lowering effects of PGAs, patients may not be well controlled on monotherapy and may require additional medication, a switch to alternative medications, or surgeries (e.g., laser trabeculoplasty and iridotomy) to achieve satisfactory IOP control. ${ }^{12,25,28}$ Greater medication adherence and persistence may be associated with the successful initial therapy because greater efficacy and low risk of side effects may result in fewer changes in therapy. ${ }^{17,29}$ For a better understanding of the PGA as initial therapy and changes of treatment patterns, there is a need to comprehensively explore the adherence and persistence with PGAs as initial therapy. It is also important to study which treatment option was chosen as an alternative treatment (i.e., second-line therapy) after the failure of an initial PGA monotherapy (i.e., first-line therapy). The results will assist prescribers in determining the optimal management of this patient population with respect to treatment patterns.

This study aimed to compare medication adherence, duration of first-line therapy, and changes in treatment after the first-line therapy among patients with glaucoma or ocular hypertension initiated on latanoprost, bimatoprost, or travoprost, using a large nationwide claims database with a 24-month follow-up period.

\section{Methods}

\section{Data Source}

This study was a retrospective observational study using administrative claims data from 2007 to 2012 from a large national health plan. The claims data included enrollment, medical, and pharmacy claims for individuals enrolled in a Medicare Advantage and Prescription Drug (MAPD) plan or fully insured commercial plan. The database covers the United States nationwide, and total membership was approximately 14 million in $2015 .^{30}$ The study was reviewed and received approval from The University of Texas Institutional Review Board.

\section{Patient Selection and Data Extraction}

Patients newly treated for glaucoma with a prescription for one of the PGAs (i.e., latanoprost, travoprost, or bimatoprost) as an initial monotherapy during the identification period (January 1 , 2008, to December 31, 2010) were identified. The date of the first PGA prescription claim during the identification period was set as the index date. Patients were required to be enrolled in an MAPD plan at least 12 months before and 24 months after the index date, with at least 2 prescription claims for the index PGAs, which is the earliest filled PGA, during the 24 months after the index date and persistent to therapy between the first 2 consecutive claims for the index PGA. A gap of up to 90 days was allowed, similar to previous studies. . $^{1524,27}$ Newly treated patients with glaucoma were defined as those who had not received a prescription for any ocular hypotensive agents or had glaucoma-related surgery in the 12-month period before the index (initial) PGA prescription. 
Patients were required to have at least 1 medical claim with a diagnosis of glaucoma or ocular hypertension at any time during the pre-index period (International Classification of Diseases, Ninth Revision, Clinical Modification [ICD-9-CM] code 365.xx) and to be aged 40 years or older on the index date. Patients with claims for any topical ocular hypotensive or any procedure code indicated for glaucoma or other ocular hypertension before the index date; filled any prescriptions for glaucoma medication other than latanoprost, travoprost, or bimatoprost; or had any procedure code indicated for glaucoma on or within 60 days after the index date were excluded. The exclusion criteria were developed to specify a certain length of first-line therapy that included only the index PGA and no other treatments.

\section{Outcome Measures}

Adherence of each index PGA was measured using medication possession ratio (MPR), which is the percentage of days for which patients possessed medication. ${ }^{31,32}$ MPR was calculated as the sum of days supply of the index PGA divided by the total days observed (730 days [24 months]) for the index PGA. All claims of index PGAs, excluding alternative medications or surgeries, during the 24-month follow-up were considered when calculating MPRs. An 80\% MPR cutoff was used to dichotomize adherent $(\geq 80 \%)$ versus nonadherent $(<80 \%)$ patients, while an MPR $>100 \%$ was truncated to $100 \%{ }^{33}$ Discontinuation of the first-line therapy was assumed to occur when there was nonpersistence, a change in the initial therapy (i.e., addition, switch, or surgery), or the end of the study period. Nonpersistence was identified when there was at least a 90-day gap between consecutive PGAs claims or between the last PGA claim and the end of study period.

If another medication was added to the first-line therapy; the index PGA was switched to alternative glaucoma medications; or surgeries (trabeculoplasty, trabeculectomy, iridotomy, and trabeculectomy) were performed after the index date, it was assumed that the first-line therapy was ineffective in managing IOP or caused significant adverse events and was defined as discontinuation. ${ }^{25}$ The duration of first-line therapy was defined as the time from the index date to discontinuation of initial therapy and was analyzed in the 24-month follow-up after the initiation of PGAs.

An "addition" was defined as an overlap of at least 60 consecutive days based on the ingredient name of the index PGA and an alternative medication. A "switch" was defined as the discontinuation of the index PGA for at least 90 consecutive days and the start of an alternative medication within 60 days of discontinuing the index PGA, with at least 60 days of persistence. The "other" category included patients who changed therapies with less than 60 consecutive days of overlap with index PGAs or who had multiple changes within 60 days.
The 6 possible pathways after first-line therapy were categorized as follows: (1) patients may stay in continuous firstline therapy without a 90-day gap between consecutive index PGAs claims during the follow-up period; (2) patients may not persist with their index PGAs and then restart their index PGAs after a gap of more than 90 days; (3) alternative glaucoma medications may be added to the index PGA; (4) patients may switch to other medications; (5) patients may have surgeries, including laser trabeculoplasty, trabeculectomy, iridotomy, and trabeculectomy; and (6) if patients were not included in any previously stated categories, they were categorized into the "other" category.

\section{Statistical Analyses}

Unbalanced baseline covariates among the PGA groups were found. Gender, race, geographic region, Charlson Comorbidity Index $(\mathrm{CCI})$ score, ${ }^{34}$ and inpatient visits were significantly different at $P<0.05$. Propensity score matching was used to reduce selection bias that may have occurred because of baseline differences among the groups so that outcome differences among PGAs could be estimated with minimal effects of confounding. Propensity scores were generated using multinomial logistic regression, adjusting for the following covariates: age, gender, race/ethnicity, geographic region, CCI score, type of glaucoma, ocular disorder, hypertension, diabetes, and the number of outpatient and inpatient visits. The study cohorts were matched using a 3-way match (nearest neighbor) with caliper set at $0.05 .^{35}$ This technique created 1:1:1 matched sets (i.e., latanoprost vs. travoprost vs. bimatoprost groups).

Demographic variables, MPR, and duration of first-line therapy were compared across groups using McNemar's tests for categorical variables and paired t-tests for continuous variables. A multivariate generalized linear model (GLM) with a normal distribution and an identity link function was used for adherence. The time to discontinuation of first-line therapy was estimated using a Cox proportional hazards model with a KaplanMeier plot. The covariates, which were measured during the 12-month pre-index period, were adjusted in the models. All analyses were conducted using SAS 9.4 (SAS Institute, Cary, NC); StataIC 14 (StataCorp, College Station, TX); and R 3.4.4 (R Foundation for Statistical Computing, Vienna, Austria). All statistical analyses were 2-tailed, and the significance level was set a priori at $P<0.05$.

\section{Results}

We identified 153,180 patients with glaucoma who had at least 1 PGA prescription in the identification period. After applying the remaining study inclusion and exclusion criteria, 7,421 patients remained. After matching, 3,888 patients (1,296 per group) were analyzed. The mean age (standard deviation [SD]) for study patients was 74.4 (7.9) years. Most patients were female (55.0\%), white $(70.8 \%)$, and resided in the 
Comparison of Prostaglandin Analog Treatment Patterns in Glaucoma and Ocular Hypertension

TABLE 1 Baseline Demographic and Clinical Characteristics by Index Prostaglandin Analog

\begin{tabular}{|c|c|c|c|c|c|c|c|}
\hline Number (Column \%) & $\begin{array}{c}\text { Total } \\
(\mathrm{N}=3,888)\end{array}$ & $\begin{array}{l}\text { Latanoprost } \\
(\mathrm{n}=1,296)\end{array}$ & $\begin{array}{l}\text { Travoprost } \\
(\mathrm{n}=1,296)\end{array}$ & $\begin{array}{c}\text { Bimatoprost } \\
(\mathrm{n}=1,296)\end{array}$ & \begin{tabular}{|c|}
$P$ Value $^{\mathrm{a}}$ \\
(Latanoprost \\
vs. Travoprost) \\
\end{tabular} & $\begin{array}{c}P \text { Value } \\
\text { (Latanoprost } \\
\text { vs. Bimatoprost) }\end{array}$ & $\begin{array}{c}P \text { Value } \\
\text { (Travoprost }^{\mathrm{a}} \\
\text { vs. Bimatoprost) }\end{array}$ \\
\hline \multicolumn{8}{|l|}{ Age, years b,c } \\
\hline Mean \pm SD & $74.4 \pm 7.9$ & $74.5 \pm 7.9$ & $74.3 \pm 7.9$ & $74.4 \pm 8.0$ & 0.533 & 0.629 & 0.880 \\
\hline $40-65$ & $255 \quad(6.6)$ & $85 \quad(6.6)$ & $85 \quad(6.6)$ & $85 \quad(6.6)$ & 1.000 & 1.000 & 1.000 \\
\hline $66-75$ & $1,753(45.1)$ & $564(43.5)$ & $603(46.5)$ & $586(45.2)$ & 0.098 & 0.333 & 0.474 \\
\hline $76-85$ & $1,601 \quad(41.2)$ & $557(43.0)$ & $505(39.0)$ & 539 (41.6) & 0.025 & 0.433 & 0.151 \\
\hline$\geq 86$ & $279 \quad(7.2)$ & $90 \quad(7.0)$ & $103 \quad(8.0)$ & $86 \quad(6.6)$ & 0.312 & 0.749 & 0.183 \\
\hline \multicolumn{8}{|l|}{ Gender $^{c}$} \\
\hline Female & $2,138 \quad(55.0)$ & $723(55.8)$ & $696(53.7)$ & $719(55.5)$ & \multirow{2}{*}{0.156} & \multirow{2}{*}{0.240} & \multirow{2}{*}{0.831} \\
\hline Male & $1,750(45.0)$ & $573(44.2)$ & $600(46.3)$ & $577(44.5)$ & & & \\
\hline \multicolumn{8}{|l|}{ Race/ethnicityc } \\
\hline White & $2,753(70.8)$ & $922(71.1)$ & $907(70.0)$ & $924(71.3)$ & 0.418 & 0.915 & 0.368 \\
\hline Black & $930(23.9)$ & $310(23.9)$ & $314(24.2)$ & $306(23.6)$ & 0.798 & 0.803 & 0.623 \\
\hline Hispanic & $112 \quad(2.9)$ & $36 \quad(2.8)$ & $41 \quad(3.2)$ & $35 \quad(2.7)$ & 0.553 & 0.901 & 0.486 \\
\hline Others & $93 \quad(2.4)$ & $28 \quad(2.2)$ & $34 \quad(2.6)$ & $31 \quad(2.4)$ & 0.431 & 0.686 & 0.701 \\
\hline \multicolumn{8}{|l|}{ Geographic region ${ }^{c}$} \\
\hline Midwest & $834(21.5)$ & $283(21.8)$ & $281(21.7)$ & $270(20.8)$ & 0.910 & 0.463 & 0.535 \\
\hline Northeast & $103 \quad(2.7)$ & $35 \quad(2.7)$ & $32 \quad(2.5)$ & $36 \quad(2.8)$ & 0.691 & 0.896 & 0.599 \\
\hline South & $2,637 \quad(67.8)$ & $870 \quad(67.1)$ & $882(68.1)$ & $885(68.3)$ & 0.519 & 0.418 & 0.872 \\
\hline West & $314 \quad(8.1)$ & $108 \quad(8.3)$ & $101 \quad(7.8)$ & $105 \quad(8.1)$ & 0.528 & 0.802 & 0.722 \\
\hline \multicolumn{8}{|l|}{ CCI score } \\
\hline Mean \pm SD & $2.45 \pm 2.3$ & $2.4 \pm 2.3$ & $2.48 \pm 2.3$ & $2.48 \pm 2.3$ & 0.305 & 0.264 & 0.929 \\
\hline 0 & $1,060 \quad(27.3)$ & $361 \quad(27.9)$ & $351 \quad(27.1)$ & $348(26.9)$ & 0.612 & 0.508 & 0.880 \\
\hline 1 & $422(10.9)$ & $155(12.0)$ & $127 \quad(9.8)$ & $140(10.8)$ & 0.067 & 0.326 & 0.378 \\
\hline 2 & $826(21.2)$ & 257 (19.8) & $279(21.5)$ & $290(22.4)$ & 0.249 & 0.079 & 0.579 \\
\hline 3 & 459 (11.8) & $171(13.2)$ & $149(11.5)$ & $139(10.7)$ & 0.195 & 0.043 & 0.541 \\
\hline 4 & 412 (10.6) & $119 \quad(9.2)$ & $152(11.7)$ & 141 (10.9) & 0.027 & 0.129 & 0.480 \\
\hline$\geq 5$ & 709 (18.2) & $233(18.0)$ & $238(18.4)$ & $238(18.4)$ & 0.775 & 0.771 & 1.000 \\
\hline \multicolumn{8}{|l|}{ Type of glaucomac } \\
\hline ACG & $23 \quad(0.6)$ & $7 \quad(0.5)$ & $8 \quad(0.6)$ & $8 \quad(0.6)$ & 0.796 & 0.796 & 1.000 \\
\hline NTG & $204 \quad(5.3)$ & $66 \quad(5.1)$ & $69 \quad(5.3)$ & $69 \quad(5.3)$ & 0.756 & 0.756 & 1.000 \\
\hline OAG & $2,845(73.2)$ & $945(72.9)$ & $947(73.1)$ & $953(73.5)$ & 0.912 & 0.659 & 0.750 \\
\hline OHT/Other & $254 \quad(6.5)$ & $78 \quad(6.0)$ & $94 \quad(7.3)$ & $82 \quad(6.3)$ & 0.131 & 0.698 & 0.300 \\
\hline Borderline glaucoma & $562(14.5)$ & $200(15.4)$ & $178(13.8)$ & $184(14.2)$ & 0.131 & 0.279 & 0.691 \\
\hline \multicolumn{8}{|l|}{ Having ocular disorder ${ }^{c}$} \\
\hline Yes & $3,003(77.2)$ & $1,007 \quad(77.7)$ & $1,004(77.5)$ & $992(76.5)$ & \multirow{2}{*}{0.878} & \multirow{2}{*}{0.445} & \multirow{2}{*}{0.547} \\
\hline No & $885(22.8)$ & $289(22.3)$ & $292(22.5)$ & $304(23.5)$ & & & \\
\hline \multicolumn{8}{|l|}{ Having hypertension ${ }^{\mathrm{c}}$} \\
\hline Yes & $2,937(75.6)$ & $978(75.5)$ & $979(75.5)$ & $980(75.6)$ & \multirow{2}{*}{0.959} & \multirow{2}{*}{0.919} & \multirow{2}{*}{0.959} \\
\hline No & $951(24.5)$ & $318(24.5)$ & $317(24.5)$ & $316(24.4)$ & & & \\
\hline \multicolumn{8}{|l|}{ Having diabetes ${ }^{c}$} \\
\hline Yes & $1,424(36.6)$ & $463(35.7)$ & $473(36.5)$ & $488(37.7)$ & \multirow{2}{*}{0.613} & \multirow{2}{*}{0.219} & \multirow{2}{*}{0.455} \\
\hline No & $2,464(63.4)$ & $833(64.3)$ & $823(63.5)$ & $808(62.4)$ & & & \\
\hline Pre-index number of all- & e outpatient $\mathrm{v}$ & & & & & & \\
\hline Mean \pm SD & $0.8 \pm 2.8$ & $0.6 \pm 2.5$ & $0.8 \pm 2.9$ & $0.8 \pm 2.9$ & 0.998 & 0.445 & 0.413 \\
\hline Pre-index all-cause inpat & visits $^{c}$ & & & & & & \\
\hline Yes & $571(14.7)$ & $169(13.0)$ & $204(15.7)$ & $198(15.3)$ & & & \\
\hline No & $3,317(85.3)$ & $1,127 \quad(87.0)$ & $1,092(84.3)$ & $1,098(84.7)$ & 0.038 & 0.077 & 0.733 \\
\hline $\begin{array}{l}\text { asignificant at } P<0.05 \text { (in b } \\
\text { bPaired t-test. } \\
\text { 'McNemar's test. } \\
\text { ACG = angle-closure glaucon } \\
\text { SD = standard deviation. }\end{array}$ & harls & $3+5$ & & & & & \\
\hline
\end{tabular}


TABLE 2 Unadjusted Medication Adherence and Duration of First-Line Therapy

\begin{tabular}{|c|c|c|c|c|c|c|c|}
\hline & $\begin{array}{c}\text { All } \\
(\mathrm{N}=3,888)\end{array}$ & $\begin{array}{l}\text { Latanoprost } \\
(\mathrm{n}=1,296)\end{array}$ & $\begin{array}{l}\text { Travoprost } \\
(\mathrm{n}=1,296)\end{array}$ & $\begin{array}{c}\text { Bimatoprost } \\
(\mathrm{n}=1,296)\end{array}$ & $\begin{array}{c}P \text { Value }^{\mathrm{a}} \\
\text { (Latanoprost vs } \\
\text { Travoprost) }\end{array}$ & $\begin{array}{c}P \text { Value }^{\mathrm{a}} \\
\text { (Latanoprost vs. } \\
\text { Bimatoprost) }\end{array}$ & $\begin{array}{c}P \text { Value }^{\mathrm{a}} \\
\text { (Travoprost vs. } \\
\text { Bimatoprost) }\end{array}$ \\
\hline $\mathrm{MPR}$, mean $\pm \mathrm{SD}^{\mathrm{b}}$ & $47.3 \pm 26.7$ & $50.1 \pm 26.8$ & $48.8 \pm 26.8$ & $43.0 \pm 26.1$ & 0.179 & $<0.0001$ & $<0.0001$ \\
\hline \multicolumn{8}{|c|}{ Adherence status, $n(\%)^{\mathrm{c}, \mathrm{d}}$} \\
\hline Adherent & $554 \quad(14.3)$ & $205(15.8)$ & $203(15.7)$ & $146 \quad(11.3)$ & \multirow{2}{*}{0.913} & \multirow{2}{*}{0.001} & \multirow{2}{*}{0.001} \\
\hline Nonadherent & $3,334 \quad(85.8)$ & $1,091 \quad(84.2)$ & $1,093(84.3)$ & $1,150(88.7)$ & & & \\
\hline $\begin{array}{l}\text { Duration of first-line } \\
\text { therapy (days), b,e } \\
\text { mean } \pm \text { SD }\end{array}$ & $358.4 \pm 236.1$ & $371.5 \pm 249.3^{c}$ & $360.7 \pm 235.0$ & $342.9 \pm 222.4$ & 0.239 & 0.003 & 0.046 \\
\hline
\end{tabular}

a Significant at $P<0.05$ (in bold).

${ }^{b}$ Paired t-test.

${ }^{c} \mathrm{McNemar}$ 's test.

${ }^{d}$ Adherence was defined as $\geq 80 \% \mathrm{MPR}$.

'Time from initiation of PGA to discontinuation of therapy.

$M P R=$ medication possession ratio; $P G A=$ prostaglandin analog; $S D=$ standard deviation

southern United States (67.8\%). More than $73 \%$ of patients had an open-angle glaucoma diagnosis in the pre-index period, while only $5.3 \%$ and $0.6 \%$ had normal tension glaucoma and angle-closure glaucoma diagnoses, respectively (Table 1).

Descriptive analyses comparing MPR and duration of firstline therapy among PGA groups are presented in Table 2. The mean MPR of index PGAs in the 24-month follow-up period was $47.3 \%$ for all patients. Only $14.3 \%$ of patients were adherent to index PGAs (cutoff: $\geq 80 \%$ ) during the 24-month follow-up. The mean MPR of the latanoprost group (50.1\%) was higher than the mean MPR of the bimatoprost group (43.0\%, $P<0.0001)$. Regarding the rate of adherence, the latanoprost group had the largest proportion of patients (15.8\%) who were adherent, while the bimatoprost group had a significantly lower rate of adherence $(11.3 \%, P=0.001)$. The mean duration of first-line therapy was 358 days for all patients. The latanoprost group had a significantly longer duration of first-line therapy compared with the bimatoprost group (372 vs. 343 days, $P=0.003$ ).

Table 3 displays results of the GLM comparing MPR by PGA groups, controlling for covariates. Patients in the bimatoprost group had a $7.2 \%$ lower MPR $(\beta=-7.21,95 \% \mathrm{CI}=-9.24$ to $-5.18, P<0.0001)$ compared with the latanoprost group. In the Cox proportional hazards regression model comparing the duration of first-line therapy by PGA groups in the 24-month follow-up, travoprost and bimatoprost groups had a $40.8 \%$ and $48.1 \%$ higher risk of discontinuation of first-line therapy compared with the latanoprost group (travoprost: $\mathrm{HR}=1.41$, 95\% CI $=1.22-1.63, P<0.0001$; bimatoprost: $\mathrm{HR}=1.48,95 \%$ $\mathrm{CI}=1.28-1.71, P<0.0001$, respectively). A Kaplan-Meier survival plot where discontinuation of first-line therapy was assessed and is shown in Appendix A (available in online article). Latanoprost patients had a significantly longer time to discontinuation of first-line therapy than other groups (logrank test: chi-square $=17.3, d f=2, P<0.001$ ).
Figure 1 shows the types of second-line therapies that occurred during the 24-month follow-up period. In total, $44.6 \%$ of patients remained in continuous first-line therapy during the follow-up period. Even when patients discontinued their index PGAs before the end of follow-up, they were assumed to have stayed in first-line therapy if they had no larger than a 90-day gap between consecutive index PGA claims. Twenty-two percent of patients resumed their index PGAs after a gap of more than 90 days between consecutive prescription claims.

Approximately $15 \%$ of patients switched from their index PGAs to alternative medications; $9.8 \%$ added another medication to the index PGA; and $4.6 \%$ of patients had surgeries after the first-line therapy. The latanoprost group had the highest proportion $(52.9 \%)$ of patients persistent on initial therapy $(P<0.0001)$. The travoprost group had the largest proportion of additional therapy $(11.4 \%, P=0.026)$, while $8.3 \%$ of patients in the latanoprost group added another medication. The overall distribution of alternative medications used in addition or switching did not show a significant difference by index PGA (Appendix B, available in online article).

The conditional logistic regression comparing the odds of adding alternative medications in the second-line therapy demonstrated that, compared with the latanoprost group, travoprost patients had $43.0 \%$ higher odds of adding another medication ( $\mathrm{OR}=1.43,95 \% \mathrm{CI}=1.10-1.86, P=0.019$; Table 4). Compared with the latanoprost group, bimatoprost patients had 21.5\% (OR=0.79, 95\% CI=0.63-0.97, $P=0.021)$ lower odds of switching to alternative medications.

\section{Discussion}

This study was designed to assess the medication adherence, duration of first-line therapy, and type of second-line therapy among patients using latanoprost, travoprost, or bimatoprost as 
TABLE 3 Statistical Models for Medication Adherence and Discontinuation of First-Line Therapy

\begin{tabular}{|c|c|c|c|c|c|c|}
\hline & \multicolumn{3}{|c|}{ Medication Adherence (MPR) ${ }^{a}$} & \multicolumn{3}{|c|}{ Discontinuation of First-Line Therapy ${ }^{b}$} \\
\hline & $\begin{array}{l}\text { Coefficient } \\
(95 \% \mathrm{CI})\end{array}$ & Wald $X^{2}$ & $P$ Value ${ }^{c}$ & $\begin{array}{l}\text { Hazard Ratio } \\
(95 \% \mathrm{CI})\end{array}$ & Estimate & $P$ Value ${ }^{c}$ \\
\hline \multicolumn{7}{|l|}{ PGA type } \\
\hline Latanoprost (ref.) & - & - & - & - & - & - \\
\hline Travoprost & $-1.32(-3.36,0.71)$ & 1.63 & 0.202 & $1.41(1.22,1.63)$ & 20.95 & $<0.0001$ \\
\hline Bimatoprost & $-7.21(-9.24,-5.18)$ & 48.31 & $<0.0001$ & $1.48(1.28,1.71)$ & 28.20 & $<0.0001$ \\
\hline Age (continuous) & $0.15(0.04,0.26)$ & 7.60 & 0.006 & $0.99(0.99,1.00)$ & 2.65 & 0.104 \\
\hline \multicolumn{7}{|l|}{ Gender } \\
\hline Male (ref.) & - & - & - & - & - & - \\
\hline Female & $1.75(0.07,3.43)$ & 4.16 & 0.041 & $0.89(0.80,1.00)$ & 3.96 & 0.047 \\
\hline \multicolumn{7}{|l|}{ Race/ethnicity } \\
\hline White (ref.) & - & - & - & - & - & - \\
\hline Nonwhite & $-2.25(-4.17,-0.34)$ & 5.31 & 0.021 & $1.17(1.03,1.33)$ & 5.81 & 0.016 \\
\hline \multicolumn{7}{|l|}{ Geographic region } \\
\hline Non-South (ref.) & - & - & - & - & - & - \\
\hline South & $3.25(1.41,5.10)$ & 11.91 & 0.001 & $0.92(0.81,1.04)$ & 1.93 & 0.165 \\
\hline CCI score (continuous) & $0.28(-0.38,0.94)$ & 0.68 & 0.408 & $0.95(0.91,1.00)$ & 4.51 & 0.034 \\
\hline \multicolumn{7}{|l|}{ Type of glaucoma } \\
\hline Non-OAG (ref.) & - & - & - & - & - & - \\
\hline OAG & $2.20(0.32,4.08)$ & 5.28 & 0.022 & $1.02(0.90,1.16)$ & 0.11 & 0.740 \\
\hline \multicolumn{7}{|l|}{ Ocular disorder } \\
\hline No (ref.) & - & - & - & - & - & - \\
\hline Yes & $-1.24(-3.23,0.75)$ & 1.49 & 0.222 & $0.88(0.77,1.00)$ & 3.60 & 0.058 \\
\hline \multicolumn{7}{|l|}{ Hypertension } \\
\hline No (ref.) & - & - & - & - & - & - \\
\hline Yes & $-1.01 \quad(-3.10,1.07)$ & 0.91 & 0.340 & $1.17(1.02,1.35)$ & 4.66 & 0.031 \\
\hline \multicolumn{7}{|l|}{ Diabetes } \\
\hline No (ref.) & - & - & - & - & - & - \\
\hline Yes & $-2.79(-5.01,-0.57)$ & 6.06 & 0.014 & $1.19(1.03,1.39)$ & 5.24 & 0.022 \\
\hline $\begin{array}{l}\text { Pre-index number of } \\
\text { outpatient visits (continuous) }\end{array}$ & $-0.01 \quad(-0.08,0.06)$ & 0.10 & 0.754 & $1.00(1.00,1.01)$ & 0.98 & 0.323 \\
\hline \multicolumn{7}{|l|}{ Pre-index inpatient visits } \\
\hline No (ref.) & - & - & - & - & - & - \\
\hline Yes & $-1.93(-4.49,0.63)$ & 2.19 & 0.139 & $1.23(1.04,1.45)$ & 5.81 & 0.016 \\
\hline \multicolumn{7}{|c|}{$\begin{array}{l}\text { aGeneralized linear model with normal distribution with the identity link function was used for medication adherence. } \\
{ }^{b} \text { Cox proportional hazard model was used for the time to discontinuation of first-line therapy. } \\
\text { cSignificant at } P<0.05 \text { (in bold). } \\
C C I=\text { Charlson Comorbidity Index; } C I=\text { confidence interval; } M P R=\text { medication possession ratio; OAG=open-angle glaucoma; } P G A=\text { prostaglandin analog; ref=reference, } \\
X^{2}=\text { chi-square. }\end{array}$} \\
\hline
\end{tabular}

initial therapies for glaucoma or ocular hypertension. Choosing initial treatment for glaucoma may not be straightforward. The characteristics of an ideal IOP-lowering eyedrop are efficacy in reducing IOP consistently over a 24-hour period to improve patient compliance regarding minimal adverse effects, no tachyphylaxis, good tolerance over time, and minimal frequency of dosage. ${ }^{36}$ Currently, PGAs are considered to closely meet these criteria (i.e., sustained efficacy and safety profile with few systemic side effects), although it is not clear which PGA is most appropriate. ${ }^{12}$

Patients with chronic conditions such as glaucoma are likely to have lower medication adherence compared with those with acute disease conditions. ${ }^{37}$ Although recent studies have documented that the lowering of IOP prevents the risk of visual field loss and slows progression from ocular hypertension to glaucoma, many patients discontinue their use of topical hypotensive agents. ${ }^{19,38}$ There are several reasons for glaucoma medication nonadherence: a lack of visual symptoms without treatment or blurring of vision with treatment, forgetfulness, inconvenient timing/frequency, and side effects. ${ }^{39,40}$

This study used MPR to measure medication adherence of PGA monotherapy. Compared with PDC, which can be used for combination therapy, MPR may be more convenient for assessing a single therapy. ${ }^{31,32}$ Because this study analyzed 
FIGURE 1 Treatment Patterns After Initiation of Prostaglandin Analog Therapy

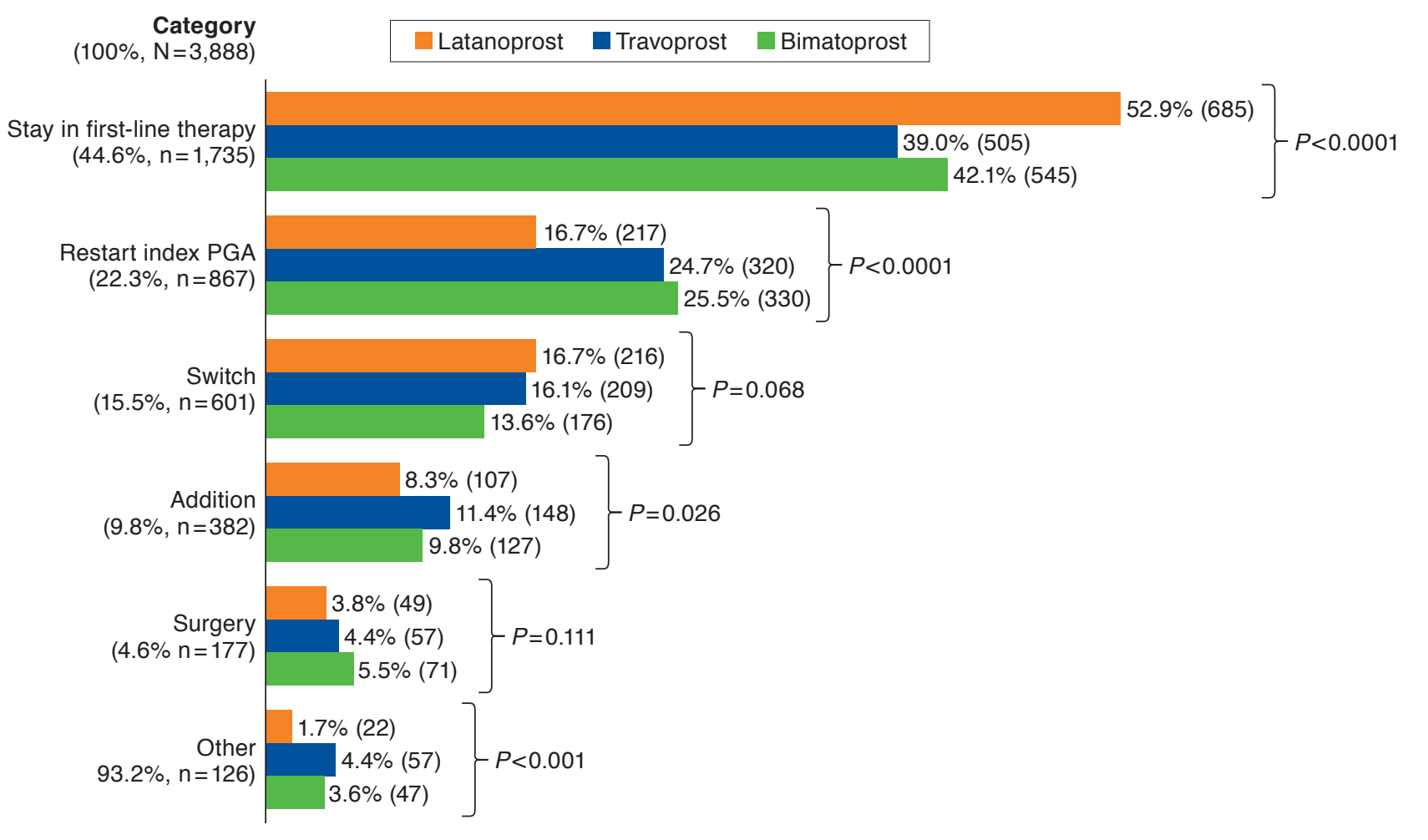

Note: Chi-square test was used.

$P G A=$ prostaglandin analog

adherence for only mono PGA therapy, MPR was the appropriate measure. The matched cohort had a mean adherence of $47.3 \%$, and $14.3 \%$ of the patients were adherent (MPR $\geq 80 \%$ ) to the index PGA during the 24-month follow-up period. This may indicate that the majority of patients discontinued their index PGA before the end of the study period, switched to alternative medications, or had a large gap between claims during the 24-month follow-up period. The latanoprost group had a higher MPR compared with the bimatoprost group. The results of the GLM also found that latanoprost users were more likely to be adherent than the bimatoprost group after controlling for covariates. This finding was comparable with previous studies assessing adherence in patients with glaucoma. A previous study reported that mean adherence (PDC) for patients prescribed latanoprost, travoprost, and bimatoprost were 66\%, $52 \%$, and $58 \%$ for the first year of follow-up, respectively. ${ }^{26}$ Another retrospective cohort study using an administrative claims database concluded that days covered in the first year were 33-42 days lower for travoprost and 21-29 days lower for bimatoprost compared with latanoprost users $(P<0.001){ }^{15}$
Glaucoma medications are only effective when they are used consistently and administered properly. Persistence to therapy is important for patients with glaucoma or ocular hypertension because those who do not continue therapy are at a higher risk of elevated IOP levels and eventual blindness. ${ }^{23}$ This study found that duration of first-line therapy was 358.4 days, on average, in the 24-month follow-up period. Latanoprost was associated with a lower risk of discontinuation compared with bimatoprost and travoprost. The discontinuation of firstline therapy was captured when a patient had more than a 90-day gap or any change in glaucoma therapy, while other studies counted only PGAs refilled days regardless of change in therapies. Although the definition was different from the other studies, the result was consistent with previous reports of latanoprost use compared with other PGAs. Reardon et al. (2010) found that travoprost and bimatoprost users were $34 \%$ more likely to have 1-year persistence compared with latanoprost users $(P<0.0001)$. In Spain, latanoprost showed a higher persistence in glaucoma treatment than comparators: $81.6 \%$ versus $22.9 \%$ for bimatoprost, $65.4 \%$ for travoprost, and $60.5 \%$ for timolol $(P<0.0001) .{ }^{16}$ The results are consistent with 
TABLE 4 Logistic Regression Comparing Odds of Adding or Switching in Second-Line Therapy

\begin{tabular}{|c|c|c|c|c|c|c|}
\hline & \multicolumn{3}{|c|}{ Adding Alternative Medications ${ }^{a}$} & \multicolumn{3}{|c|}{ Switching to Alternative Medications ${ }^{a}$} \\
\hline & $\begin{array}{l}\text { Odds Ratio } \\
(95 \% \mathrm{CI})\end{array}$ & Wald $X^{2}$ & $P$ Value ${ }^{b}$ & $\begin{array}{l}\text { Odds Ratio } \\
(95 \% \mathrm{CI})\end{array}$ & Wald $X^{2}$ & $P$ Value ${ }^{b}$ \\
\hline \multicolumn{7}{|l|}{ PGA type } \\
\hline Latanoprost (ref.) & - & - & - & - & - & - \\
\hline Travoprost & $1.43(1.10-1.86)$ & 5.50 & 0.019 & $0.96(0.78-1.19)$ & 0.81 & 0.368 \\
\hline Bimatoprost & $1.21(0.92-1.58)$ & 0.01 & 0.923 & $0.79(0.63-0.97)$ & 5.33 & 0.021 \\
\hline Age (continuous) & $1.01(0.99-1.02)$ & 0.86 & 0.353 & $1.00(0.99-1.01)$ & 0.27 & 0.601 \\
\hline \multicolumn{7}{|l|}{ Gender } \\
\hline Male (ref.) & - & - & - & - & - & - \\
\hline Female & $0.99(0.80-1.23)$ & 0.01 & 0.939 & $1.12(0.94-1.34)$ & 1.59 & 0.208 \\
\hline \multicolumn{7}{|l|}{ Race/ethnicity } \\
\hline White (ref.) & - & - & - & - & - & - \\
\hline Nonwhite & $1.23(0.97-1.56)$ & 2.97 & 0.085 & $0.81 \quad(0.66-0.99)$ & 4.23 & 0.040 \\
\hline \multicolumn{7}{|l|}{ Geographic region } \\
\hline Non-South (ref.) & - & - & - & - & - & - \\
\hline South & $1.16(0.91-1.48)$ & 1.44 & 0.230 & $1.29(1.06-1.57)$ & 6.41 & 0.011 \\
\hline CCI score (continuous) & $1.00(0.99-1.00)$ & 0.94 & 0.331 & $1.00(0.99-1.00)$ & 0.01 & 0.909 \\
\hline \multicolumn{7}{|l|}{ Type of glaucoma } \\
\hline Non-OAG (ref.) & - & - & - & - & - & - \\
\hline OAG & $1.56(1.20-2.04)$ & 10.91 & 0.001 & $0.91 \quad(0.75-1.11)$ & 0.87 & 0.350 \\
\hline \multicolumn{7}{|l|}{ Ocular disorder } \\
\hline No (ref.) & - & - & - & - & - & - \\
\hline Yes & $1.05(0.81-1.35)$ & 0.13 & 0.721 & $1.23(0.99-1.53)$ & 3.48 & 0.062 \\
\hline \multicolumn{7}{|l|}{ Hypertension } \\
\hline No (ref.) & - & - & - & - & - & - \\
\hline Yes & $0.91(0.70-1.18)$ & 0.52 & 0.471 & $0.97(0.78-1.20)$ & 0.10 & 0.751 \\
\hline \multicolumn{7}{|l|}{ Diabetes } \\
\hline No (ref.) & - & - & - & - & - & - \\
\hline Yes & $0.87(0.68-1.12)$ & 1.15 & 0.283 & $0.96(0.78-1.18)$ & 0.15 & 0.697 \\
\hline $\begin{array}{l}\text { Pre-index number of } \\
\text { outpatient visits (continuous) }\end{array}$ & $1.00(0.99-1.01)$ & 0.82 & 0.366 & $1.00(0.99-1.01)$ & 0.42 & 0.518 \\
\hline \multicolumn{7}{|l|}{ Pre-index inpatient visits } \\
\hline No (ref.) & - & - & - & - & - & - \\
\hline Yes & $1.06(0.77-1.47)$ & 0.14 & 0.705 & $1.06(0.81-1.38)$ & 0.19 & 0.662 \\
\hline
\end{tabular}

previous research showing that latanoprost decreased IOP levels effectively. ${ }^{23}$ A better tolerated first-line therapy will decrease the need for changes in treatment because poor persistence with ocular hypotensive agents is likely to limit a vision loss from glaucoma. ${ }^{17}$

The types of second-line therapies were different by index PGAs. Latanoprost had the largest proportion (52.9\%) of patients remaining on first-line therapy $(P<0.0001)$. However, that group had the lowest proportion (16.7\%) of patients who restarted their index PGAs $(P<0.0001)$, indicating that if latanoprost failed to manage glaucoma progression, latanoprost was more likely to be terminated compared with other PGAs. The travoprost group was more likely to add alternative medications $(P=0.019)$. The medications used for addition and switching in second-line therapy were not significantly different among PGA groups; however, timolol was the most common additional medication. Timolol can be dosed once a day, compared with dorzolamide and brimonidine, which require multiple daily doses. ${ }^{41}$

Regarding the methods to define the type of second-line therapy, unlike a previous study that categorized only additions and switches as second-line therapy, ${ }^{25}$ this study included the surgery option, as well as another pathway ("other"), for patients who did not fall neatly into the addition, switch, or surgery arms. Only $4.6 \%$ of patients had surgery after the initial therapy, and there was no significant difference by index PGAs. Potential problems with compliance, allergies, and side effects may be reduced by laser trabeculoplasty, which can improve outflow 
with a laser instead of additional drugs. ${ }^{41}$ The "other" category (3.2\%) included all other therapy changes that did not meet the definition of addition, switching, or surgeries. Because patients changed treatments multiple times within short periods, the second-line therapy could not be determined appropriately.

There is no standard guideline for choosing alternative glaucoma medications after a trial with a PGA. For patients who already used a PGA, the mean diurnal IOP-lowering achieved with the addition of an alpha-2 adrenergic agonist, a beta adrenergic antagonist, or a CAI were not significantly different, whereas the side-effect profiles and nocturnal IOP-lowering efficacy varied. ${ }^{42}$ The factors that physicians should consider in selecting glaucoma treatment options include IOP-lowering efficacy, visual field, the general health status of patients, and local ocular and systemic side effects, as well as the tolerability, dosing frequency, convenience, and cost to the patient. ${ }^{12,41}$

\section{Limitations}

This study had some potential limitations. Because of the nature of claims databases, this study's findings may have been influenced by potential errors in coding, omissions in claims data, and unmeasured factors such as psychosocial variables. Additionally, there were no clinical efficacy measurements available to include in the analyses, although clinical outcomes might be a factor influencing the treatment patterns. Baseline IOP and the extent of difficulty in using eyedrops can be confounding factors to adjust for differences among PGA groups in regression models; however, these variables were unavailable in the claims database.

This study assumed that all filled medications were used by patients as prescribed. Similar to other persistency studies, the use of retrospective claims data does not allow an assessment of patient or physician reasons for treatment choices or discontinuing or changing therapy. In addition, the study is based on a large, representative sample of adults enrolled in MAPDs, so the results may not be generalizable to patients who are uninsured or enrolled in commercial health plans, Medicaid, or Medicare beneficiaries enrolled in non-MAPD plans. Some of these groups are typically known to struggle with medication adherence and utilization rates, out-of-pocket costs, or treatment patterns and may have different outcomes from those observed in this study. ${ }^{26}$ It should be noted that more than 93\% of study patients were aged 65 years and over. Substantial low adherence is common for the elderly because they may have other conditions or disabilities and a higher chance of bothersome side effects. ${ }^{38}$

\section{Conclusions}

Many patients had suboptimal medication use of topical glaucoma medications. This study found that latanoprost users had greater odds of adherence and less risk of discontinuing initial monotherapy than those who initiated bimatoprost or travoprost. The choice of initial therapy may be an important consideration to improve adherence and persistence in routine clinical practice settings. The results provide additional insights to ophthalmologists, emphasizing the need to monitor patient adherence and provide education on the importance of adherence. While earlier glaucoma studies analyzed only initial therapy, this study analyzed the change in therapy and alternative therapies. ${ }^{15,16,22-25}$ Ophthalmologists need to be aware that depending on initial PGA use, the odds of switching or adding therapies may be different in second-line therapy.

The results of the study showed that patients who had latanoprost as an initial therapy were significantly more likely to adhere and persist to the treatment compared with those who had bimatoprost. In the 24-month follow-up period, latanoprost patients showed a significantly lower risk of discontinuing their first-line therapy than other PGAs groups. After discontinuation of first-line therapy, the travoprost group was more likely to add alternative medications than latanoprost users.

\section{Authors}

JI HAENG HEO, PhD, Health Outcomes Division, College of Pharmacy, The University of Texas at Austin, and Genesis Research, Hoboken, New Jersey. KAREN L. RASCATI, PhD; JAMES P. WILSON, PhD; KENNETH A. LAWSON, PhD; and KRISTIN M. RICHARDS, PhD, Health Outcomes Division, College of Pharmacy, The University of Texas at Austin. RADHIKA NAIR, PhD, Humana, Louisville, Kentucky.

AUTHOR CORRESPONDENCE: Ji Haeng Heo, PhD,

Genesis Research, 5 Marine View Plaza, Hoboken, NJ 07030.

Tel.: 888.503.2680; E-mail: jihaeng@genesisrg.com.

\section{DISCLOSURES}

No outside funding supported this study. All authors except Heo and Nair are employed by The University of Texas at Austin College of Pharmacy. Heo was with the Health Outcomes Division, The University of Texas at Austin College of Pharmacy during a portion of this study and is employed by Genesis Research. Nair is employed by Humana. The authors have no financial relationships relevant to this article to disclose.

This study was presented as a poster at the 2016 International Society for Pharmacoeconomics and Outcomes Research Annual Meeting, May 2016, Washington, DC.

\section{REFERENCES}

1. Emptage NP, Mizuiri D, Bagly L, Lum FC. Primary Angle Closure. Preferred Practice Pattern. American Academy of Ophthalmology. New York: Elsevier; 2016. Available at: https://www.aaojournal.org/article/S01616420(15)01271-3/pdf. Accessed July 22, 2019.

2. National Eye Institute.Change of cases between 2000 and 2010. Retrieved May 15, 2016. Available at: https://nei.nih.gov/eyedata/glaucoma. Accessed July 8, 2019

3. Grehn F, Stamper R, eds. Glaucoma: Progress III. Essentials in Ophthalmology. Berlin, Heidelberg: Springer; 2009. 
4. Pascolini D, Mariotti SP. Global data on visual impairments 2010. World Health Organization. 2012. Available at: https://www.who.int/blindness/ GLOBALDATAFINALforweb.pdf?ua=1. Accessed July 8, 2019.

5. Distelhorst JS, Hughes GM. Open-angle glaucoma. Am Fam Physician. 2003;67(9):1937-44.

6. Emptage NP, Mizuiri D, Bagly L, Lum FC. Primary Open-Angle Glaucoma Suspect. Preferred Practice Pattern. American Academy of Ophthalmology. New York: Elsevier; 2016. Available at: https://www.aaojournal.org/article/ S0161-6420(15)01278-6/pdf. Accessed July 22, 2019.

7. van der Valk R, Webers CA, Lumley T, Hendrikse F, Prins MH, Schouten JS. A network meta-analysis combined direct and indirect comparisons between glaucoma drugs to rank effectiveness in lowering intraocular pressure. J Clin Epidemiol. 2009;62(12):1279-83.

8. Whitson JT. Glaucoma: a review of adjunctive therapy and new management strategies. Expert Opin Pharmacother. 2007;8(18):3237-49.

9. Boland MV, Ervin AM, Friedman DS, et al. Comparative effectiveness of treatments for open-angle glaucoma: a systematic review for the U.S Preventive Services Task Force. Ann Intern Med. 2013;158(4):271-79.

10. Li N, Chen XM, Zhou Y, Wei ML, Yao X. Travoprost compared with other prostaglandin analogues or timolol in patients with open-angle glaucoma or ocular hypertension: meta-analysis of randomized controlled trials Clin Experiment Ophthalmol. 2006;34(8):755-64.

11. Sambhara D, Aref AA. Glaucoma management: relative value and place in therapy of available drug treatments. Ther Adv Chronic Dis. 2014;5(1):30-43.

12. Emptage NP, Mizuiri D, Bagly L, Lum FC. Primary Open-Angle Glaucoma. Preferred Practice Pattern. American Academy of Ophthalmology. New York: Elsevier; 2016. Available at: https://www.aaojournal.org/article/S01616420(15)01276-2/pdf. Accessed July 22, 2019

13. Sleath B, Blalock S, Covert D, et al. The relationship between glaucoma medication adherence, eye drop technique, and visual field defect severity. Ophthalmology. 2011;118(12):2398-402

14. Mansberger SL. Are you compliant with addressing glaucoma adherence? Am J Ophthalmol. 2010;149(1):1-3.

15. Reardon G, Schwartz GF, Kotak S. Persistence on prostaglandin ocular hypotensive therapy: an assessment using medication possession and days covered on therapy. BMC Ophthalmol. 2010;10:5.

16. Arias A, Schargel K, Ussa F, Canut MI, Robles AY, Sanchez BM. Patient persistence with first-line antiglaucomatous monotherapy. Clin Ophthalmol. 2010;4:261-67.

17. Nordstrom BL, Friedman DS, Mozaffari E, Quigley HA, Walker AM. Persistence and adherence with topical glaucoma therapy. Am J Ophthalmol. 2005;140(4):598-606.

18. Schwartz GF, Reardon G, Mozaffari E. Persistency with latanoprost or timolol in primary open-angle glaucoma suspects. Am J Ophthalmol. 2004;137(1 Suppl):S13-16

19. Dasgupta S, Oates V, Bookhart BK, Vaziri B, Schwartz GF, Mozaffari E. Population-based persistency rates for topical glaucoma medications measured with pharmacy claims data. Am J Manag Care. 2002;8(10 Suppl): S255-61.

20. Zhou Z, Althin R, Sforzolini BS, Dhawan R. Persistency and treatment failure in newly diagnosed open angle glaucoma patients in the United Kingdom. Br J Ophthalmol. 2004;88(11):1391-94.

21. Diestelhorst M, Schaefer CP, Beusterien KM, et al. Persistency and clinical outcomes associated with latanoprost and beta-blocker monotherapy: evidence from a European retrospective cohort study. Eur J Ophthalmol. 2003;13(Suppl 4):S21-29

22. Reardon G, Schwartz GF, Mozaffari E. Patient persistency with ocular prostaglandin therapy: a population-based, retrospective study. Clin Ther. 2003;25(4):1172-85.
23. Reardon G, Schwartz GF, Mozaffari E. Patient persistency with topical ocular hypotensive therapy in a managed care population. Am J Ophthalmol. 2004;137(1 Suppl):S3-12.

24. Rait JL, Adena MA. Persistency rates for prostaglandin and other hypotensive eyedrops: population-based study using pharmacy claims data. Clin Experiment Ophthalmol. 2007;35(7):602-11.

25. Zimmerman TJ, Hahn SR, Gelb L, Tan H, Kim EE. The impact of ocular adverse effects in patients treated with topical prostaglandin analogs: changes in prescription patterns and patient persistence. J Ocul Pharmacol Ther. 2009;25(2):145-52.

26. Stein JD, Shekhawat N, Talwar N, Balkrishnan R. Impact of the introduction of generic latanoprost on glaucoma medication adherence. Ophthalmology. 2015;122(4):738-47.

27. Wilensky J, Fiscella RG, Carlson AM, Morris LS, Walt J. Measurement of persistence and adherence to regimens of IOP-lowering glaucoma medications using pharmacy claims data. Am J Ophthalmol. 2006;141 (1 Suppl):S28-33.

28. Schmier JK, Hulme-Lowe CK, Covert DW. Adjunctive therapy patterns in glaucoma patients using prostaglandin analogs. Clin Ophthalmol. 2014:8:1097-104.

29. Muir KW, Lee PP. Glaucoma medication adherence: room for improvement in both performance and measurement. Arch Ophthalmol. 2011;129(2):243-45

30. Humana. 2015 annual report: health through partnership. Available at: https://humana.gcs-web.com/static-files/277b9d7c-67e2-43aa-b97d5d493ce7eb8d. Accessed July 8, 2019.

31. Steiner JF, Prochazka AV. The assessment of refill compliance using pharmacy records: methods, validity, and applications. J Clin Epidemiol. 1997;50(1):105-16.

32. Peterson AM, Nau DP, Cramer JA, Benner J, Gwadry-Sridhar F, Nichol M. A checklist for medication compliance and persistence studies using retrospective databases. Value Health. 2007;10(1):3-12.

33. Cramer JA, Roy A, Burrell A, et al. Medication compliance and persistence: terminology and definitions. Value Health. 2008;11(1):44-47.

34. Needham DM, Scales DC, Laupacis A, Pronovost PJ. A systematic review of the Charlson Comorbidity Index using Canadian administrative databases: a perspective on risk adjustment in critical care research. J Crit Care. 2005;20(1):12-19.

35. Rassen JA, Shelat AA, Franklin JM, Glynn RJ, Solomon DH, Schneeweiss S. Matching by propensity score in cohort studies with three treatment groups. Epidemiology. 2013;24(3):401-09.

36. Kulkarni SV, Damji KF, Buys YM. Medical management of primary open-angle glaucoma: best practices associated with enhanced patient compliance and persistency. Patient Prefer Adherence. 2008;2:303-14.

37. Skalicky SE, Goldberg I. Adherence and persistence: the challenges for glaucoma medical therapy. Asia Pac J Ophthalmol (Phila). 2013;2(6):356-61.

38. Gurwitz JH, Glynn RJ, Monane M, et al. Treatment for glaucoma: adherence by the elderly. Am J Public Health. 1993;83(5):711-16.

39. Konstas AG, Maskaleris G, Gratsonidis S, Sardelli C. Compliance and viewpoint of glaucoma patients in Greece. Eye (Lond). 2000;14(Pt 5):752-56.

40. Patel SC, Spaeth GL. Compliance in patients prescribed eyedrops for glaucoma. Ophthalmic Surg. 1995;26(3):233-36.

41. Asrani S. When a prostaglandin drop isn't enough. Review of Ophthalmology. April 5, 2016. Available at: https://www.reviewofophthalmology.com/article/when-a-prostaglandin-drop-isnt-enough. Accessed July 8, 2019

42. Tanna AP, Lin AB. Medical therapy for glaucoma: what to add after a prostaglandin analogs? Curr Opin Ophthalmol. 2015;26(2):116-20. 


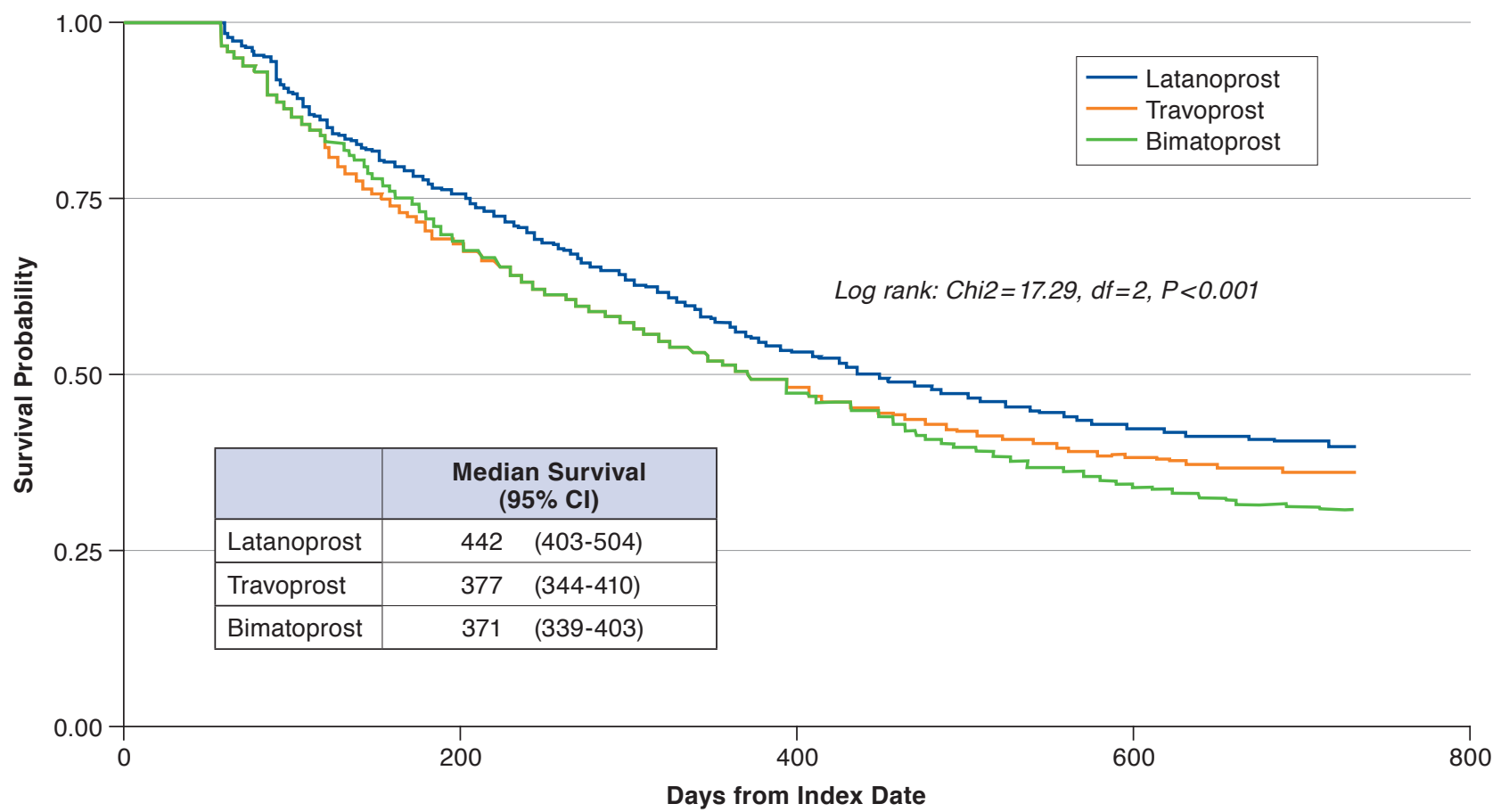

Chi ${ }^{2}=$ chi-square; $C I=$ confidence interval; $d f=$ degrees of freedom . 
APPENDIX B Medication Use in Addition/Switch Therapy by Index Prostaglandin Analog

\begin{tabular}{|c|c|c|c|c|c|c|c|c|c|c|}
\hline \multirow[b]{2}{*}{ Medication } & \multicolumn{5}{|c|}{ Addition Therapy, n (\%) } & \multicolumn{5}{|c|}{ Switch Therapy, n (\%) } \\
\hline & All & Latanoprost & Travoprost & Bimatoprost & $P$ Value $^{\mathrm{a}}$ & All & Latanoprost & Travoprost & Bimatoprost & $P$ Value ${ }^{a}$ \\
\hline Total & $382(100)$ & $107(100)$ & $148(100)$ & $127(100)$ & & $601(100)$ & $216(100)$ & $209(100)$ & $176(100)$ & \\
\hline Beta blockers & $132(34.6)$ & $45(42.1)$ & $48(32.4)$ & $39(30.7)$ & 0.151 & $168(28.0)$ & $57(26.4)$ & $61(29.2)$ & $50(28.4)$ & 0.803 \\
\hline Timolol & $127(33.3)$ & $44(41.1)$ & $46(31.1)$ & $37(29.1)$ & & $164(27.3)$ & $56(25.9)$ & $59(28.2)$ & $49(27.8)$ & \\
\hline Levobunolol & $2(0.5)$ & $1 \quad(0.9)$ & $1 \quad(0.7)$ & $0 \quad(0)$ & & $3(0.5)$ & $1 \quad(0.5)$ & $2(1.0)$ & $(0)$ & \\
\hline Betaxolol & $3(0.8)$ & $0 \quad(0.0)$ & $1 \quad(0.7)$ & $2(1.6)$ & & $1 \quad(0.2)$ & $0 \quad(0.0)$ & $0 \quad(0.0)$ & $1 \quad(0.6)$ & \\
\hline $\mathrm{PGA}^{\mathrm{b}}$ & $26 \quad(6.8)$ & $8 \quad(7.5)$ & $10 \quad(6.8)$ & $8 \quad(6.3)$ & 0.938 & $226(37.6)$ & $97(44.9)$ & $73(34.9)$ & $56(31.8)$ & 0.018 \\
\hline Latanoprost & $4 \quad(1.1)$ & $0 \quad(0.0)$ & $0 \quad(0.0)$ & $4 \quad(3.2)$ & & $48 \quad(8.0)$ & $0 \quad(0.0)$ & $51(24.4)$ & $30(17.1)$ & \\
\hline Travoprost & $5 \quad(1.3)$ & $1 \quad(0.9)$ & $0 \quad(0.0)$ & $4 \quad(3.2)$ & & $62(10.3)$ & $65(30.2)$ & $0 \quad(0.0)$ & $26(14.8)$ & \\
\hline Bimatoprost & $17 \quad(4.5)$ & $7 \quad(6.5)$ & $10 \quad(6.8)$ & $(0)$ & & $116(19.3)$ & $32(14.8)$ & $22(10.5)$ & $(0)$ & \\
\hline $\begin{array}{l}\text { Alpha agonist: } \\
\text { brimonidine }\end{array}$ & $73(19.1)$ & $15 \quad$ (14) & $29(19.6)$ & $29(22.8)$ & 0.228 & $92(15.3)$ & $31(14.4)$ & $31(14.8)$ & $30(17.1)$ & 0.741 \\
\hline $\begin{array}{l}\text { Combination of alpha } \\
\text { agonist and beta } \\
\text { blockers: brimonidine } \\
\text { and timolol }\end{array}$ & $54(14.1)$ & $11(10.3)$ & $25(16.9)$ & $18(14.2)$ & 0.327 & $32 \quad(5.3)$ & $8 \quad(3.7)$ & $12 \quad(5.7)$ & $12(6.8)$ & 0.372 \\
\hline $\begin{array}{l}\text { Combination of CAIs } \\
\text { and beta blockers: } \\
\text { dorzolamide and timolol }\end{array}$ & $34 \quad(8.9)$ & $10 \quad(9.4)$ & $8 \quad(5.4)$ & $16(12.6)$ & 0.111 & $42 \quad(7.0)$ & (6) & $16 \quad(7.7)$ & $13 \quad(7.4)$ & 0.779 \\
\hline CAIs & $41(10.7)$ & $12(11.2)$ & $20(13.5)$ & $9 \quad(7.1)$ & 0.225 & $17 \quad(2.8)$ & $5 \quad(2.3)$ & $4 \quad(1.9)$ & $8 \quad(4.6)$ & 0.255 \\
\hline Brinzolamide & $30 \quad(7.9)$ & $6 \quad(5.6)$ & $16(10.8)$ & $8 \quad(6.3)$ & & $13 \quad(2.2)$ & $3 \quad(1.4)$ & 3 (1.4) & $7 \quad(4.0)$ & \\
\hline Dorzolamide & 11 (2.9) & $6 \quad(5.6)$ & $4 \quad(2.7)$ & $1 \quad(0.8)$ & & $4 \quad(0.7)$ & $2(0.9)$ & $1 \quad(0.5)$ & $1 \quad(0.6)$ & \\
\hline Others & $22 \quad(5.8)$ & $6 \quad(5.6)$ & $8 \quad(5.4)$ & $8 \quad(6.3)$ & 0.948 & $24 \quad(4.0)$ & $5 \quad(2.3)$ & $12(5.7)$ & $7 \quad(4.0)$ & 0.197 \\
\hline
\end{tabular}

${ }^{a}$ Chi-square test; significant at $P<0.05$ (in bold).

${ }^{b}$ The glaucoma treatment guideline does not recommend multiple PGAs in a therapy. Patients might refill second PGAs before running out of index PGA, and they no longer administer index PGAs.

$C A I=$ carbonic anhydrase inhibitor; $P G A=$ prostaglandin analog. 